\title{
Low Z Impurity Ion Extraction from TFTR Ion Sources
}

J. H. Kamperschroer, L. R. Grisham, F. A. Newman, T. E. O'Connor, T. N.

Stevenson, A. von Halle, M. D. Williams, and K. E. Wright

Princeton Plasma Physics Laboratory, Princeton University, PO Box 451, Princeton, $N J 08543$

PPPL --2897

DE93 011978

\begin{abstract}
TFTR deuterium neutral beams have been operated unintentionally with significant quantities of extracted water ions. Water has been observed with an Optical Multichannel Analyzer (OMA) during beam extraction when small water leaks were present within the arc chamber. These leaks were thermally induced with the contamination level increasing linearly with pulse length. $6 \%$ of the beam current was attributed to water ions for the worst leak, corresponding to an instantaneous value of $12 \%$ at the end of a $1.5 \mathrm{~s}$ pulse. A pre-calorimeter collimator was damaged as a result of this operation. A similar contamination is observed during initial operation of ion sources exposed to air. This latter contamination is attributed to the synthesis, from adsorbed air, of either $D_{2} O$ or the indistinguishable $\mathrm{ND}_{3}$. Initial operation of new ion sources typically produces a contamination level of $\sim 2 \%$. These impurities are reduced to undetectable levels after 50 to 100 beam pulses. Once a water molecule is present in the plasma generator, it is predominantly ionized rather than dissociated, resulting in the extraction of only trace amounts of hydrogenated ions. The addition of water to
\end{abstract}


the extracted beam also reduces the optimum perveance, moving the typical underdense operating point closer to optimum, causing the frequency of grid faults to increase.

Close to $90 \%$ of the water extracted from ion sources with water leaks was deuterated, implying that the potential exists for the production of tritiated water during TFTR's forthcoming DT operation. Isotope exchange in the plasma generator takes place rapidly and is believed to be surface catalyzed. The primary concern is with $O$ implanted into beam absorbers recombining with tritium, and the subsequent hold up of $\mathrm{T}_{2} \mathrm{O}$ on cryopanels. Continuous surveillance with the OMA diagnostic during DT operation will ensure that ion sources with detectable water are not operated with tritium. 


\section{INTRODUCTION}

Several ion sources on the TFTR neutral beam injection system ${ }^{1}$ were operated for a short time with arc voltage ramping near the end of the pulse. ${ }^{2}$ Small water leaks in the ion sources, present only during source operation, were responsible for this phenomenon. Through the use of the Optical Multichannel Analyzer (OMA), ${ }^{3}$ the presence of Doppler-shifted partial energy deuterium, or hydrogen, i.e, water contamination, was identified as the cause of the problem. Water has long been known as a trace impurity in the extracted beams on TFTR and machines at other facilities. ${ }^{4,5}$ In this instance, the quantity observed far exceeded previous levels.

Despite this difficulty, neutral beam reliability for TFTR physics experiments remained high throughout the run period. ${ }^{1}$ Ion sources operated reliably for months with smail water leaks. Only when source operation deteriorated with unstable arc discharges were the subject ion sources replaced. Causes of the leaks were subsequently discovered, and remedial action taken to prevent similar occurrences in the future.

Following removal of the leaky ion sources, operation of the replacement sources was observed. The surfaces of the new sources had adsorbed air during maintenance, and a contamination level of several percent was detected. Cleanup required several days of operation.

During the planned power breakeven experiments on TFTR, half of the neutral beam injectors will be operated with tritium. ${ }^{6}$ Implications of water leaks into ion sources during such operation are discussed in section IV. 


\section{EXPERIMIFNTAL APPARATUS}

\section{A. Neutral Beam Injection System}

Each TFTR beamline has three Common Long Pulse Ion Sources (CLPIS) ${ }^{7}$ developed by the Lawrence Berkeley Laboratory (LBL). Figure 1 is a crosssectional through the narrow dimension of the source. Two subassemblies can be seen: the plasma generator, on top, and the accelerator, slightly below the center of the figure. Positive ions, created in the discharge between the tungsten cathodes and the copper anode, are accelerated in the three gap accelerator through a potential difference of up to $120 \mathrm{kV}$. The accelerator structure, $12 \mathrm{~cm}$ by $43 \mathrm{~cm}$, consists of four grids, each an assembly of 56 water-cooled molybdenum grid rails. The plasma generator floats at high voltage with the potential decreasing as the ions propagate through the accelerator, reaching ground potential at the exit grid. Located around the periphery of the plasma generator, near the first grid, are six water-cooled Langmuir probes used to monitor plasma density and plasma uniformity, and serving as a real time interlock on plasma stability.

After exiting the ion source, the beam enters the neutralizer, a rectangular duct $15 \mathrm{~cm}$ wide, $50 \mathrm{~cm}$ tall, $250 \mathrm{~cm}$ long. Here, it collides with gas from the ion source $\left(\sim 0.7 \mathrm{~Pa}-\mathrm{m}^{3} / \mathrm{s}\right)$ and gas fed directly into the neutralizer $\left(\sim 2.0 \mathrm{~Pa}-\mathrm{m}^{3} / \mathrm{s}\right)$. Charge changing collisions convert the incident ion beam into a near equilibrium mixture of ions and neutrals by the time particles reach the end of the neutralizer. 8 Some of the atoms are collisionally excited and emit light, which is observed via an OMA tuned to the $\mathrm{H} \alpha \mathrm{D} \alpha$ line. 


\section{B. Optical Multichannel Analyzer}

Data regarding beam contamination were obtained with the OMA diagnostic, a computer controlled two-dimensional vidicon detector attached to the output of a $1 \mathrm{~m}$ SPEX spectrometer. ${ }^{3}$ Water is observed indirectly via Doppler-shifted Balmer$\alpha$ emission from the $H$, and/or $D$, dissociation products of accelerated water ions. The emission from these fragments is separated in wavelength from that of the three main beam constituents because their velocity is approximately one-third of the full-energy $D$. The OMA views the beam in the direction perpendicular to the horizontal grid rails at a location $65 \mathrm{~cm}$ downstream of the exit grid. The angle, $\theta$, between the OMA's line of sight and the beam is $60^{\circ}$, providing a Doppler shift, towards blue, of the Balmer- $\alpha$ emission of the fast atoms relative to the unshifted Balmer- $\alpha$ line of the thermal gas. The magnitude of the shift is $\Delta \lambda=\lambda_{0} \frac{v}{c} \cos \theta$, where $\lambda_{0}$ is the wavelength of the unshifted Balmer- $\alpha$ emission, $v$ is the speed of the particle, and $\mathrm{c}$ is the speed of light.

From the intensities of the Doppler-shifted emissions of the full-, half-, and third-energy D, from known cross sections, 9,10 and from an estimate of the gas line density from the ion source to the point of observation, the extracted ion beam composition can be deduced. $3,4,11$ Additionally, the widths of the Doppler-shifted lines provide a measure of the beam divergence. $4,12,13$

A typical OMA spectrum, with background subtracted, is shown in figures 2 and 3 for the case of $50.6 \mathrm{~A}$ of deuterium ions extracted at $95.6 \mathrm{kV}$ for $1.2 \mathrm{~s}$. The abscissa is detector channel number (wavelength) and the ordinate is the number of counts in each of the 500 channels. At the nominal dispersion of 8.3 channels $/ \AA$, the detector covers $60 \AA$. Evident left to right in figure 2 are the Doppler-shifted full-, half-, and third-energy $D$ lines in the center, and the 
unshifted $\mathrm{D} \alpha$ line at the extreme right. Figure 3 presents the same data with an expanded ordinate. Several small lines of a few hundred counts, e.g., in channels 368 and 413, are ascribed to molecular deuterium emission.

Spectral data are acquired during the entire beam pulse, with the number of counts accumulating in each channel over the length of the pulse. Beam composition, therefore, is a time average over the pulse duration.

A wavelength calibration was necessary to determine the energy of the hydrogenic water dissociation products. This calibration was performed using nine neon lines spanning the 500 channels of the detector. It was found that the detector channels were more closely spaced (by about 10\%) at the edge of the detector than in the center. An accuracy can be assigned to the calibration based upon its prediction of the location of the half-energy $D$ peak from the locations of the third-energy $D$ peak and the unshifted $D \alpha$ peak. Using this measure, the wavelength calibration is accurate to $\pm 1 / 2$ channel in identifying the Dopplershifted water dissociation products.

\section{RESULTS}

\section{A. Indirect Observation of Extracted Water Ions}

Data were taken during the episode of arc voltage ramping as the pulse length was stretched from its nominal value of $1 \mathrm{~s}$ upwards toward $2 \mathrm{~s}$. Spectra for the ion source exhibiting the greatest amount of water contamination are given in figures 4-6, for pulse lengths of $1.1 \mathrm{~s}, 1.3 \mathrm{~s}$, and $1.5 \mathrm{~s}$, respectively. $43 \mathrm{~A}$ of ions

were extracted at $94 \mathrm{kV}$ in each case. Compared to figure 3, Doppler-shifted Balmer- $\alpha$ emission between the third-energy $D$ and the unshifted $D \alpha$ line are 
prevalent, implying that a portion of the extracted beam ions are hydrogenbearing molecular ions. As the pulse length increased, the relative contamination level increased. Time averaged impurity fractions for the cases of figures $4-6$ were $3.8 \%, 5.6 \%$, and $6.2 \%$, respectively (assuming that the contaminating molecules to be water). Since the increase is nearly linear with time, an estimate of the instantaneous impurity content of the beam at the end of the $1.5 \mathrm{~s}$ pulse is $12 \%$. Source autopsies revealed that the leaky components were either the Langmuir probes or accelerator grid masks. Both are actively cooled with water. Upgrades have been instituted to prevent similar leaks in the future. Since water leaks were found, it is deduced that the hydrogen-bearing molecular ion contamination observed during this period of source operation was water.

Due to the lack of cross sections for the dissociation of incident $\mathrm{H}_{2} \mathrm{O}^{+}$and $\mathrm{D}_{2} \mathrm{O}^{+}$, the extracted water fraction is computed assuming a thick neutralizer at the observation point. ${ }^{14}$ Support for this assumption is given in section IV.

Additional evidence for the presence of water is the appearance of an unshifted $H \alpha$ line. This line, isotopically shifted by $3 \AA$ from $D \alpha$, and evident at channel 498 in figures $4-6$, is absent under normal operation. Unshifted Ha emission can arise from the excitation of thermal hydrogen (from the dissociation of water in the plasma generator) drifting out of the ion source, or from hydrogen dissociated from thermal water in the neutralizer. The ratio of the unshifted Ha intensity to that of $\mathrm{D} \alpha$ in figure 6 is $<0.05$. This value is an upper limit since the intensity of the unshifted $D \alpha$ line places the detector well into saturation.

An expanded view of the water dissociation product emissions of figure 6, given in figure 7, indicates that the line shape is not a simple gaussian. It is the sum of at least two unresolved lines. Candidate parent ions for this convolution of Doppler-shifted $\mathrm{H} \alpha / \mathrm{D} \alpha$ lines are $\mathrm{D}_{2} \mathrm{O}^{+}, \mathrm{HDO}^{+}, \mathrm{H}_{2} \mathrm{O}^{+}, \mathrm{DO}^{+}$, and $\mathrm{HO}^{+}$. Based upon 
the spectrometer/detector calibration, the predicted locations of Balmer- $\alpha$ emission from the extraction of these ions are as given in table 1.

A least squares fit to the data in figure 7 was made to determine the relative contributions of the possible parent ions. A gaussian distribution was assumed for each of the six lines. All line were assigned the same width. Each had its centroid located at the channel given in table 1 . Individual amplitudes, and the common line width, were varied until a best fit was attained. The results of this fit are indicated in figure 8, where the data are plotted as solid circles and the fit as open circles. Contributions from $\mathrm{DO}^{+}$and $\mathrm{HO}^{+}$were negligible. Contributions from each of the other four lines are plotted on the bottom with no offset. The sum of these four peaks, with an added 800 count background, is shown as open circles. Agreement with the data is excellent. The molecular deuterium lines to either side of the water dissociation product lines were excluded from the fit. Composite contributions are: $56 \%$ from $\mathrm{D}_{2} \mathrm{O}^{+}, 22 \%$ from $\mathrm{DHO}^{+}(\mathrm{H \alpha}), 14 \%$ from $\mathrm{H}_{2} \mathrm{O}^{+}$, and $9 \%$ from $\mathrm{DHO}^{+}(\mathrm{D} \alpha)$. D $\alpha$ emission dominates $\mathrm{H} \alpha$ emission by a factor of four.

\section{B. Observation of Ex tracted Hydrogen}

Hydrogen accelerated as molecular hydrogen ions has also been observed. This is clear in figure 9, an expanded view of figure 6. Large lines are the usual Doppler-shifted full-energy, half-energy, and third-energy $D \alpha$ lines. Small numbered lines were absent in the water-free case of figure 3. Table 2 lists these by their parent ion and Doppler shift relative to that of the full-energy $D$. An isotope shift separates $H \alpha$ and $D \alpha$ emissions with the same relative Doppler-shift. Some of the designated lines are readily visible, others are barely discernable. 
The deuterium fragment of $\mathrm{H}_{2} \mathrm{D}^{+}$overlays the peak of the primary half-energy line and is totally obscured. No full-energy $\mathrm{H}$ was apparent. The line to the right of the $\mathrm{H}_{2}{ }^{+}$generated $\mathrm{H} \alpha(\# 1)$ is one of several attributed to molecular deuterium.

The relative abundances of the trace hydrogen molecules were obtained from least squares fits to the three primary beam components. Channels comprising the trace molecules were ignored in the fits. Subtraction of the fit from the raw data provided estimates of the magnitudes of the traces lines. From this calculation of the line intensities and from cross sections for excitation of Balmer$\alpha$ emission, $, 9,10$ estimates of the extracted ion fractions were made. The results are $0.02 \% \mathrm{H}_{2}+, 0.5 \% \mathrm{DH}^{+}, 0.2 \% \mathrm{D}_{2} \mathrm{H}^{+}$, and $0.02 \% \mathrm{H}_{2} \mathrm{D}^{+}$. Uncertainties in the magnitudes of the line intensities, and in the neutralizer line density, yield an uncertainty in the calculation of these molecular ion fractions of $\pm 25 \%$.

Little $\mathrm{H}_{2}{ }^{+}$or $\mathrm{H}_{2} \mathrm{D}^{+}$were extracted since they possess two trace atoms each and are unlikely to be created in a deuterium-rich environment. $\mathrm{DH}^{+}$and $\mathrm{D}_{2} \mathrm{H}^{+}$, on the other hand, are more plentiful because of the abundance of deuterium for hydrogen to react with.

\section{Secondary Effects of Water Upon Beam Operation}

The introduction of water into an ion source has a measurable effect upon the beam composition and divergence. Data from the three pulses used above, plus a fourth short pulse, are given in Table 3. Shown are the beam current (I), voltage (V), perveance $\left(\mathrm{I}^{1.5}\right)$, extracted $\mathrm{D}^{+}, \mathrm{D}_{2}{ }^{+}, \mathrm{D}_{3}{ }^{+}$, and water fractions, and full-width at half-maximum of the full-energy $D^{0}$ line. The width of the $D^{0}(E)$ line is widest for the case with the least amount of water contamination. This trend is well supported since the error bars, \pm 1 channel, are much less than the total spread in 
line width. It is also apparent that the ratio of the $\mathrm{D}^{+}$to $\mathrm{D}_{2}^{+}$fractions increases as the water level increases, while the absolute value of the $\mathrm{D}^{+}$fraction is unchanged.

\section{Clean Up of Replacement Ion Sources}

Four of the twelve ion sources used on TFTR have experienced water contamination to some degree during this period of time. These sources were eventually removed and repaired. CMA data was obtained during initial operation of two of the replacement sources. Prior to any attempt at beam extraction on a new ion source, the arc was conditioned by slowly increasing the arc power over many pulses until $100 \mathrm{~kW}$ was attained. Such operation provides a thorough discharge cleaning of the plasma generator. Still, initial beam operation indicated a contamination level of several percent (assuming the contaminant is water). These values approach that of all but the worst case leak reported above. Without the preceding arc operation, it is certain that the initial contamination would have been higher.

Figure 10 shows data from the initial operation of the two ion sources, with the contamination level plotted versus shot number. Approximately 50 one second beam pulses were required to reduce the contamination to the limit of detectability. 


\section{DISCUSSION}

The introduction of water into TFTR ion sources is deleterious for several reasons. First, it affects source operation, making it difficult to maintain a stable arc discharge. With arc stability adversely affected, reliable beam operation becomes formidable. Second, oxygen ions, both positively and negatively charged, are deflected by the bending magnet onto inadequately cooled components. Third, water will exchange with tritium in the arc chamber producing tritiated water. Since the derived air concentration of tritiated water is 25,000 times less than that of elemental tritium, ${ }^{15}$ the conversion of elemental tritium to tritiated water increases the radiological hazards associated with the TFTR DT experiments. Tritiated water production impacts the tritium inventory since it is pumped on the liquid nitrogen surfaces of the cryopanel and will not be released until the cryopanels are warmed to room temperature. Oxygen implanted into beam absorbers is an additional source of tritiated water since it can recombine with implanted tritium.

The water contaminated beam operation reported above has damaged the precalorimeter collimator. The focal properties of stiff ions passing through the magnet, in conjunction with long pulse operation ( $>1 \mathrm{~s}$ ), are the conjectured cause. $^{2}$ A related concern is beam deposition onto components in the negative ion direction. There is evidence of such ions striking the differential pumping baffle below the pre-calorimeter collimator and on the magnet support structure. Given an equilibrium oxygen negative ion fraction of $\sim 10 \%$ in a hydrogen target, ${ }^{16}$ it is clear that sufficient negative oxygen ions can be produced to create an observable effect. Since all ion sources show evidence of impurity bombardment of the differential pumping baffle, its origin is clearly air adsorption in the plasma 
generator. While not a serious thermal problem for present operation, $\mathrm{O}^{-}$is a concern for potential upgrades of the beamline to long pulse operation.

Energetic oxygen implanted into beamline components will recombine with tritium during the beam pulse to form tritiated water. This is due to the fact that oxygen is much more likely to be released in the form of water than oxygen, ${ }^{17}$ and oxygen will recombine with implanted hydrogen isotopes to produce water. ${ }^{18}$ Hopefully, most of the implanted oxygen will be removed by subsequent deuterium operation as $\mathrm{D}_{2} \mathrm{O}$, although significant production of tritiated water will occur during any tritium pulse that deposits oxygen. Tritium recovery following the Preliminary Tritium Experiment on the Joint European Torus (JET) has proven to be more difficult than anticipated. ${ }^{19}$

Upon entering the neutralizer, extracted water ions dissociate, producing 0 , $\mathrm{H}$, and $\mathrm{D}$ ions and/or atoms. Interest here lies in the fate of the oxygen which carries away $\sim 80 \%$ of the incident energy. For nominal $100 \mathrm{kV}$ source operation, the equilibrium oxygen fractions are: $63 \% 0,25 \% \mathrm{O}^{+}, 10 \% \mathrm{O}^{-}$, and $2 \% \mathrm{O}^{++} .16$ Oxygen atoms are predominately deposited on the calorimeter, or injected into the tokamak. $\mathrm{O}^{+}$is deflected by the magnet, with $\sim 50 \%$ being deposited on the bottom of the ion dump, the remainder spilling over onto the calorimeter entrance scraper. ${ }^{2}$ Trajectories of $\mathrm{O}^{++}$have yet, to be computed, but they will be deposited in the vicinity of the calorimeter. $\mathrm{O}^{-}$will strike the pumping baffles and magnet. The primary constituents, $\mathrm{O}$ and $\mathrm{O}^{+}$, will recombine with implanted hydrogen isotopes to produce water. The fraction of this water that is tritiated remains to be determined.

Contamination of TFTR neutral beams has arisen from two sources: water leaks and adsorbed monolayers of air. The leaks were thermally induced since the leak rate icreased with pulse length and there was no evidence of leaking 
between beam pulses. Approximately one gram-mole of water was extracted from the sum of all pulses during operation of the leakiest source. A second grammole was obtained from the cumulative operation of three other leaky sources during the same time period. The potential hazard from water contaminated beam operation during tritium operation is seen in the fact that the quantity of deuterium reacting to form water during this water-leak episode exceeds the maximum on-site inventory of elemental tritium.

Water is present in the air adsorbed on the ion source surfaces during maintenance as was seen in figure 10 . However, most of the water produced in the discharge comes from the more plentiful adsorbed oxygen combining with deuterium. This loosely bound layer of air cleans up after of order one hundred beam pulses. The integrated quantity of water detected ( -3.5 torr-1) during cleanup corresponds to approximately 100 monolayers. While this level of contamination is significant, it is only a small fraction of that experienced during the water leak.

It is likely that ammonia is also produced during discharges with adsorbed air. The resultant Doppler-shifted Balmer- $\alpha$ emission from deuterons produced via dissociation of $\mathrm{D}_{2} \mathrm{O}$ and $\mathrm{ND}_{3}$ are indistinguishable. Cross sections for the production of Balmer- $\alpha$ emission from ammonia incident on deuterium have not been measured. If, for the purposes of this discussion, it is assumed that the ammonia and water production rates in the discharge, and the Balmer- $\alpha$ emission cross sections are the same, then the Balmer- $\alpha$ emission from ammonia would be approximately twice that from water, for the case of an air contaminated ion source. In such a case, the contamination given in figure 10 is approximately $2 / 3$ due to nitrogen and $1 / 3$ due to oxygen. No unshifted $H \alpha$ is observed during the cleanup of adsorbed air because of the small quantities of adsorbed water relative to nitrogen and oxygen. 
Cleanup of hydrogen isotopes proceeds much faster than the cleanup of adsorbed air. It takes only one moderate arc pulse, or less, to remove any adsorbed gas from prior operation with a different isotope. ${ }^{8}$ Of order one monolayer of gas is involved in this cleanup. Preceding source operation would have removed the many layers of adsorbed air.

A large unknown with adsorbed air is the cleanup during the arc conditioning which precedes beam operation. Contamination levels were highest during the first beam pulses following arc conditioning. Even more water is presumed liberated during arc conditioning discharges. While the potential exists for the production of tritiated water during arc conditioning, it can be easily avoided by performing all conditioning with deuterium.

Water contaminated beam operation at LBL has also resulted in the observation of $\mathrm{D}_{2} \mathrm{O}^{+}$extraction. ${ }^{4}$ Only a single Doppler-shifted water dissociation. product line was apparent in their data. The LBL spectrum had a small unshifted $\mathrm{H} \alpha$ line, indicative of the presence of $\mathrm{H}_{2} \mathrm{O}$. Our experience is somewhat different. A water leak in a TFTR ion source produces a Doppler-shifted water dissociation product line with two distinct components as well as an unshifted H $\alpha$ line. This $\mathrm{H} \alpha$ line was even apparent during arc discharges. During clean up of adsorbed air, the unshifted $\mathrm{H} \alpha$ line is absent. The signal to noise ratio during air cleanup is not great enough to state that the water dissociation peak contains only $\mathrm{D}_{2} \mathrm{O}$ or $\mathrm{ND}_{3}$ fragments with no $\mathrm{HDO}$ or $\mathrm{H}_{2} \mathrm{O}$ (i.e., no $\mathrm{H} \alpha$ emission), but that is our conjecture.

The dependence of the beam divergence upon water contamination level, as presented in Table 3, cannot be explained by the small changes in perveance among the pulses listed. Based upon a typical perveance scan, ${ }^{20}$ the change in divergence $\left[D^{0}(E)\right.$ line width] over the range of perveances in Table 3 is only $7 \%$. 
This is contrasted with an observed $34 \%$ change in the line width as the water contamination increased from $1 \%$ to $6 \%$. What has transpired is that the introduction of water has altered the optimum perveance of the scurce through a change in the effective mass of the extracted ions. At the nominal composition of the beam, the average mass of the extracted deuterium ions is 2.56. The addition of $6 \%$ deuterated water changed the average mass of extracted ions to 3.6. Optimal perveance was concomitantly reduced from 1.7 to 1.43 microperv ( $10^{-6}$ $\mathrm{AV}^{-1.5}$ ). Since the data of Table 3 was taken at a perveance of 1.47 microperv, the introduction of $6 \%$ water decreased the optimum perveance to a value close to that being run. Instead of being underdense, the new operating point was very close to optimum perveance and the divergence decreased. The result was improved divergence and an increase in the number of faults with time during the pulse.

The accuracy of the calculation of the relative water content of the beam hinges on the validity of the assumption of a thick neutralizer target. Unfortunately, cross sections for the collisional dissociation of water on hydrogen are not known. Inaccuracies in the calculation of the water content result since cross sections for the production of $\mathrm{H} \alpha$ emission from beam constituents ${ }^{9,10}$ and water ${ }^{21}$ can be different. The water dissociation cross section is at least $2 \times 10^{-17}$ $\mathrm{cm}^{2}$ at the velocities of interest. ${ }^{21}$ However, this is only the cross section for dissociation that produces $\mathrm{H} \alpha$ emission. A mean free path of $\sim 350 \mathrm{~cm}$ is implied based on this process alone. While the total dissociation cross section is probably much larger, the assumption of a thick target for an $O$ beam cannot be justified on this basis.

It has been shown that as a deuterium beam propagates down a neutralizer, the relative magnitudes of the $\mathrm{H} \alpha$ emissions from the three primary extracted ionic constituents are insensitive to the neutralizer line density traversed. ${ }^{12} \mathrm{~A}$ 
similar effect is true for incident water. It is assumed that cross sections for the production of $\mathrm{H \alpha}$ emission from an incident water molecule on $\mathrm{H}_{2}$ are the same as those for $\mathrm{H}_{2}$ on water vapor at the same velocity. With this assumption and data from reference 21, the cross section for $\mathrm{H} \alpha$ emission from incident $100 \mathrm{keV}$ $\mathrm{D}_{2} \mathrm{O}\left(2 \times 10^{-17} \mathrm{~cm}^{2}\right)$ is only slightly different from the contributions of the weighted sum of the two hydrogenic dissociation products of water $\left(2 \times 8.2 \times 10^{-18} \mathrm{~cm}^{2}\right)$. Therefore, the calculation of the water content of the beam only weakly depends upon whether the water has dissociated or not.

A water molecule in the arc chamber experiences a total ionization cross section of $2 \times 10^{-16}$ to $3 \times 10^{-16} \mathrm{~cm}^{2}$ due to 30 to $100 \mathrm{eV}$ electrons. ${ }^{23-25}$ The primary ionization product is $\mathrm{H}_{2} \mathrm{O}^{+}$, with $\mathrm{H}^{+}$and $\mathrm{OH}^{+}$produced in lesser quantities. At lower electron energies, the $\mathrm{H}_{2} \mathrm{O}^{+}$fraction becomes more dominant, e. g., $90 \%$ $\mathrm{H}_{2} \mathrm{O}^{+}$at $5 \mathrm{eV}^{23}$ versus $80 \%$ at $100 \mathrm{eV} .{ }^{26}$ For an electron density in the plasma generator of $1.6 \times 10^{12} \mathrm{~cm}^{-3}, 27$ the mean free path for water ionization is $20 \mathrm{~m}$, implying that water molecules will reach a surface before suffering ionization by collision with electrons. The total ionization cross section for $\mathrm{H}_{2}$ is $1 \times 10^{-16} \mathrm{~cm}^{2}$ at $70 \mathrm{eV} .^{28}$ Its dissociation cross section is similar in magnitude, peaking at the lower energy of $20 \mathrm{eV} .^{28}$ Given that it is easier to ionize water than hydrogen, the gas efficiency for water should be greater than for hydrogen, i.e., it should exceed 50\%.8 Water admitted to the plasma generator should be ionized and extracted, only a small fraction should escape as thermal water molecules. In addition, the extracted water should be accompanied by only a small amount of $\mathrm{OH}^{+}$.

Upon reaching a clean arc chamber wall, a water molecule will most likely dissociate. ${ }^{17}, 18,29$ The walls in these ion sources are assumed to be clean since the working gas can be switched without cleanup. ${ }^{8}$ It is postulated that the arc discharge maintains the anode in a state of cleanliness. An oxygen atom on this 
surface will recombine with the dominant hydrogen specie, deuterium, producing heavy water. ${ }^{18}$ Deuterated ammonia is produced the same manner.

The exchange reaction $\mathrm{H}_{2}+\mathrm{D}_{2} \Leftrightarrow 2 \mathrm{HD}$ was studied soon after the discovery of deuterium. It was found that a mixture of $\mathrm{H}_{2}$ and $\mathrm{D}_{2}$ attained equilibrium concentrations of $\mathrm{H}_{2}, \mathrm{HD}$, and $\mathrm{D}_{2}$ in a few minutes. ${ }^{30}$ This reaction has been studied extensively since its pure protium equivalent is the simplest chemical reaction known and is amenable to theoretical modelling. ${ }^{31}$ Subsequent research has found that the reaction proceeds via $\mathrm{D}+\mathrm{H}_{2} \Leftrightarrow \mathrm{HD}+\mathrm{H}$ and $\mathrm{H}+\mathrm{D}_{2} \Leftrightarrow \mathrm{HD}+\mathrm{D}$, with $\mathrm{H}$ and $\mathrm{D}$ produced via surface catalyzed dissociation. These reactions attain equilibrium in seconds at $1000 \mathrm{~K}$ and $100 \mathrm{~Pa} .32$ On molybdenum surfaces, such as on the CLPIS's accelerator grids, only a single surface interaction is necessary to reach equilibrium. ${ }^{33}$ Since measurable $\mathrm{H}_{2} \mathrm{O}^{+}$and $\mathrm{HDO}^{+}$were extracted from our sources, it is concluded that the efficiency of surface catalyzed isotope exchange, while high, is less than $100 \%$.

Finally, there is the issue of isotope exchange of the hydrogen atoms and molecules produced via the dissociation of water with deuterium. Cross sections have been measured for $\mathrm{H}^{+}+\mathrm{D}_{2} \rightarrow \mathrm{HD}^{+}+\mathrm{D}$ and $\mathrm{H}^{+}+\mathrm{D}_{2} \rightarrow \mathrm{D}^{+}+\mathrm{HD}$. The $\mathrm{HD}^{+}$ production cross section reaches a peak of $3 \times 10^{-17} \mathrm{~cm}^{2}$ at $4 \mathrm{eV}$ while that for $\mathrm{D}^{+}$ production is resonant, increasing to many times $10^{-16} \mathrm{~cm}^{2}$ below $1 \mathrm{eV} .{ }^{34-37}$ For a deuterium ion source pressure of $0.5 \mathrm{~Pa}$, the mean free path for $\mathrm{HD}$ production is of order $35 \mathrm{~cm}$, a distance comparable to the size of the arc chamber. Mixed molecules should be produced via this reaction.

Cross sections have also been measured for $\mathrm{H}_{2}{ }^{+}+\mathrm{D} \rightarrow \mathrm{H}+\mathrm{HD}^{+}$. They are $5 \times 10^{-16} \mathrm{~cm}^{2}$ at $2 \mathrm{eV}$, and exceed $10^{-15} \mathrm{~cm}^{2}$ below $1 \mathrm{eV}{ }^{38}$ While this reaction has a large cross section, little $\mathrm{H}_{2}{ }^{+}$is present to fuel it.

Given the efficiencies of the processes above, little $\mathrm{H}^{+}$is expected in a water contaminated beam. Isotopic exchange processes in a plasma are efficient. 
Hydrogen freed from water by wall catalyzed isotope exchange would rapidly combine with deuterium to form $\mathrm{HD}$, the dominant hydrogenated ion observed. The $\mathrm{HD}^{+}$fraction of the beam would be less than the $\mathrm{D}_{2} \mathrm{O}^{+}$fraction, as observed, since the gas efficiency of $H D$ is less than that of water.

\section{ACKNOWLADGEMIENTS}

The authors would like to acknowledge discussions with Drs. K. L. Wilson and Derek Stork, and correspondence with Dr. H. B. Gilbody. Thanks is also given to the neutral beam mechanical and ion source technicians, ion source operators, and shift supervisors without whose help nothing would ever get done. This work was supported by the U. S. Department of Energy under contract DEAC02-CHO-3073. 


\section{RHFERINCES}

${ }^{1}$ T. Stevenson, J. Kamperschroer, L. Dudek, L. Grisham, R. Newman, T. O'Connor, A. von Halle, and M. D. Williams, in Proceedings of the Fourteenth Symposium on Fusion Engineering, San Diego, 1991 (IEEE, New York, 1992), Vol. 2, p. 908.

2J. H. Kamperschroer, T. N. Stevenson, K. E. Wright, F. Dahlgren, L. E. Dudek, L. R. Grisham, R. A. Newman, T. E. O'Connor, M. E. Oldaker, S: Ramakrishnan, S. Schweitzer, A. von Halle, and M. D. Williams, in Proceedings of the Fourteenth Symposium on Fusion Engineering, San Diego, 1991 (IEEE, New York, 1992), Vol. 2, p. 915.

${ }^{3}$ J. H. Kamperschroer, H. W. Kugel, M. A. Reale, S. L. Hayes, G. A. Johnson, J. L. Lowrance, P. A. Shah, P. Sichta, B. W. Sleaford, M. D. Williams, and P. M. Zucchino, Rev. Sci. Instrum. 58, 1362 (1987).

${ }^{4}$ C. F. Burrell, W. S. Cooper, R. R. Smith, and W. F. Steele, Rev. Sci. Instrum. 61, 1451 (1980).

5Y. Okumura, Y. Mizutani, Y. Ohara, and T. Shibata, Rev. Sci. Instrum. 52, 1 (1981).

${ }^{6}$ L. R. Grisham, H. F. Dylla, M. D. Williams, K. Wright, and R. Causey, J. Vac. Sci. Technol. A 7, 944 (1989).

${ }^{7}$ M. C. Vella, W. S. Cooper, P. A. Pincosy, R. V. Pyle, P.D. Weber, and R. P. Wells, Rev. Sci. Instrum. 59, 2357 (1988).

8J. H. Kamperschroer, G. M. Gammel, H. W. Kugel, L. R. Grisham, T. N. Stevenson, A. von Halle, M. D. Williams, and T. T. C. Jones, J. Vac. Sci. Technol. A 7, 83 (1989). 
${ }^{9}$ I. D. Williams, J. Geddes, and H. B. Gilbody, J. Phys. B: At. Mol. Phys. 15, 1377 (1982).

${ }^{10}$ I. D. Williams, J. Geddes, and H. B. Gilbody, J. Phys. B: At. Mol. Phys. 16, L765 (1983).

${ }^{11}$ G. H. Deschamps, H. D. Falter, R. S. Hemsworth, and P. Massmann, in Proceedings of the Fifteenth Symposium on Fusion Technology, Utrecht, 1988 (Elsevier, Amsterdam, 1989), Vol. 1, p. 588.

12 J. H. Kamperschroer, G. Schilling, and A. L. Roquemore, Rev. Sci. Instrum. 61, 3101 (1990).

${ }^{13}$ J. F. Bonnal, G. Bracco, C. Breton, C de Michelis, J. Druaux, M. Mattioli, R. Oberson, and J. Ramette, J. Phys. D: Appl. Phys. 15, 805 (1982).

${ }^{14}$ The thick neutralizer approximation for the water fraction computation originated in the OMA analysis code conceived by the late Dr. C. F. Burrell.

15 International Commission on Radiological Protection, Publication 30 (Pergamon, New York, 1979).

${ }^{16}$ T. Jorgensen, Jr., C. E. Kuyatt, W. W. Lang, D. C. Lorents, and C. A. Sautter, Phys. Rev. 140, A1481 (1965).

${ }^{17}$ P. A. Thiel and T. E. Madey, Surf. Sci. Rep. 7, 211(1987).

18I. Langmuir, Trans. Faraday Soc. 17, 621 (1922).

${ }^{19}$ H. D. Falter, D. Ciric, G. H. Deschamps, H. P. L. de Esch, P. Massmann, and L. Svensson, to be published in Proceedings of the Seventeenth Symposium on Fusion Technology, Rome, 1992.

${ }^{20}$ J. H. Kamperschroer, L. R. Grisham, L. E. Dudek, G. M. Gammel, G. A. Johnson, H. W. Kugel, L. Lagin, T. E. O'Connor, P. A. Shah, P. Sichta, T. N. Stevenson, A. von Halle, and M. D. Williams, Rev. Sci. Instrum. 60, 3377 (1989). 
${ }^{21}$ F. B. Yousif, J. Geddes, and H. B. Gilbody, J. Phys. B: At. Mol. Phys. 19, 217 (1986).

${ }^{22}$ C. F. Burrell, W. S. Cooper, W. F. Steele, and R. R. Smith, in Proceedings of the Seventh Symposium on Engineering Problems of Fusion Research, Knoxville, 1977 (IEEE, New York, 1977), Vol. 1, p. 374.

${ }^{23}$ J. Schutten, F. J. de Heer, H. R. Moustafa, A. J. H. Boerboom, and J. Kistemaker, J. Chem. Phys. 44, 3924 (1966).

${ }^{24}$ F. W. Lampe, J. L. Franklin, and F. H. Field, J. Ar. Chem. Soc. 79, 6129 (1957).

${ }^{25}$ C. E. Melton, J. Phys. Chem. 74, 582 (1970).

${ }^{26}$ M. M. Mann, A. Hustrulid, and J. T. Tate, Phys. Rev. 58, 340 (1940).

${ }^{27}$ C. F. Chan, C. F. Burrell, and W. S. Cooper, J. Appl. Phys. 54, 6119 (1983).

${ }^{28}$ C. F. Barnett, J. A. Ray, E. Ricci, M. I. Wilker, E. W. McDaniel, E. W. Thomas, and H. B. Gilbody, Oak Ridge National Laboratory Report, ORNL-5207, Vol. 2 (1977).

${ }^{29}$ P. R. Norton, in The Chemical Physics of Solid Surfaces and Heterogeneous Catalysis, Vol. 4, edited by D. A. King and D. P. Woodruff (Elsevier, Amsterdam, 1982).

${ }^{30}$ A. Farkas and L. Farkas, Proc. Royal Soc. London A152, 124 (1935).

31 J. Hirschfelder, H. Eyring, and B. Topley, J. Chem. Phys. 4, 170 (1936).

${ }^{32}$ G. Pratt and D. Rogers, J. Chem. Soc., Faraday Trans. 1 72, 1589 (1976).

${ }^{33}$ G. E. Moore and F. C. Unterwald, J. Chem. Phys. 48, 5378(1968).

${ }^{34}$ W. B. Maier II, J. Chem. Phys. 54, 2732 (1971).

${ }^{35}$ G. Ochs and E. Teloy, J. Chem. Phys. 61, 4930 (1974).

36J. R. Krenos, R. K. Preston, R. Wolfgang, and J. C. Tully, J. Chem. Phys. 60, 1634 (1974). 
${ }^{37}$ M. G. Holliday, J. T. Muckerman, and L. Friedman, J. Chem. Phys. 54, 1058 (1971).

${ }^{38}$ K. L. Wendell and P. K. Rol, J. Chem. Phys. 61, 2059 (1974). 


\section{FIGURE CAPTIONS}

Figure 1. Cross-sectional view of the Common Long Pulse Ion Source showing both the arc chamber and accelerator assemblies.

Figure 2. Typical deuterium beam spectrum taken with the 500 channel Optical Multi-channel Analyzer.

Figure 3. Same as figure 2, but with the ordinate expanded to show the details of the full-, half-, and third-energy $\mathrm{D}$ components of the beam.

Figure 4. Water contaminated OMA spectrum from a $1.1 \mathrm{~s}$ deuterium beam pulse for the ion source with the worst water leak.

Figure 5. Water contaminated OMA spectrum from a $1.3 \mathrm{~s}$ deuterium beam pulse for the ion source with the worst water leak.

Figure 6. Water contaminated OMA spectrum from a $1.5 \mathrm{~s}$ deuterium beam pulse for the ion source with the worst water leak.

Figure 7. The data of figure 6 , with the abscissa expanded, showing the line shape of the emission of the hydrogenic products of water dissociation in the neutralizer.

Figure 8. Fit, open circles, to the data, solid circles, of figure 7 . The fit includes left to right, $\mathrm{HDO}^{+}(\mathrm{D \alpha}), \mathrm{D}_{2} \mathrm{O}^{+}, \mathrm{H}_{2} \mathrm{O}^{+}$, and $\mathrm{HDO}^{+}(\mathrm{H \alpha})$. 
Figure 9. Details of the OMA spectrum of figure 6 due to extracted hydrogenated ions: 1) $\mathrm{H}_{2}^{+}$, 2) $\left.\mathrm{DH}^{+}, 3\right) \mathrm{H}_{2} \mathrm{D}^{+}$, and 4) $\mathrm{D}_{2} \mathrm{H}^{+}$.

Figure 10. Contamination of two replacement ion sources (one open circles, one solid circles) versus shot number. 
Table 1. Candidate parent ions for the Doppler-shifted waterdissociation product line.

Doppler-shifted atom

$\mathrm{H}$

D

$\mathrm{H}$

D

D

$\mathrm{H}$
Darent

$\mathrm{H}_{2} \mathrm{O}^{+}$

$\mathrm{D}_{2} \mathrm{O}^{+}$

$\mathrm{HDO}^{+}$

$\mathrm{HDO}^{+}$

$\mathrm{DO}^{+}$

$\mathrm{HO}^{+}$ channel

398.0

387.1

400.6

384.7

382.1

395.2 
Table 2. Deuterium and hydrogen atoms present in a water contaminated beam, their parent ions, and the relative Doppler shift of the Balmer- $\alpha$ emission.

$\begin{array}{cccc}\text { fievure 6 designation } & \text { atom (energy) } & \text { parention } & \text { Doppler shit } \\ & \mathrm{H}(\mathrm{E}) & \mathrm{H}^{+} & 1.41 \\ & \mathrm{D}(\mathrm{E}) & \mathrm{D}^{+} & 1 \\ 1 & \mathrm{H}(\mathrm{E} / 2) & \mathrm{H}_{2}^{+} & 1 \\ 2 & \mathrm{D}(2 \mathrm{E} / 3) & \mathrm{DH}^{+} & 0.82 \\ 2 & \mathrm{H}(\mathrm{E} / 3) & \mathrm{DH}^{+} & 0.82 \\ & \mathrm{D}(\mathrm{E} / 2) & \mathrm{D}_{2}^{+} & 0.71 \\ & \mathrm{D}(\mathrm{E} / 2) & \mathrm{H}_{2} \mathrm{D}^{+} & 0.71 \\ 3 & \mathrm{H}(\mathrm{E} / 4) & \mathrm{H}_{2} \mathrm{D}^{+} & 0.71 \\ 4 & \mathrm{D}(2 \mathrm{E} / 5) & \mathrm{D}_{2} \mathrm{H}^{+} & 0.63 \\ 4 & \mathrm{H}(\mathrm{E} / 5) & \mathrm{D}_{2} \mathrm{H}^{+} & 0.63\end{array}$


Table 3. Dependence of beam species and divergence upon the water contamination of the beam.

I $\quad \mathrm{V}$ pervegice $\mathrm{D}^{+} \quad \mathrm{D}_{2}{ }^{+} \quad \mathrm{D}_{\mathbf{3}}^{+}$water linewidth

41.9 A $\quad 93.9 \mathrm{kV} \quad 1.46 \times 10^{-6} \mathrm{AV}^{-1.5} \quad 71.7 \% \quad 24.0 \% .3 .3 \% \quad 1.0 \% \quad 24$ channels

$\begin{array}{lll}42.6 & 93.8 \quad 1.48\end{array}$

$\begin{array}{lllll}71.4 & 21.6 & 3.2 & 3.8 & 19\end{array}$

$42.9 \quad 93.9 \quad 1.49$

$\begin{array}{lllll}71.2 & 20.4 & 2.9 & 5.6 & 18\end{array}$

$\begin{array}{lll}42.3 & 93.8 & 1.47\end{array}$

$\begin{array}{lllll}70.5 & 20.4 & 3.0 & 6.2 & 18\end{array}$ 
8920107

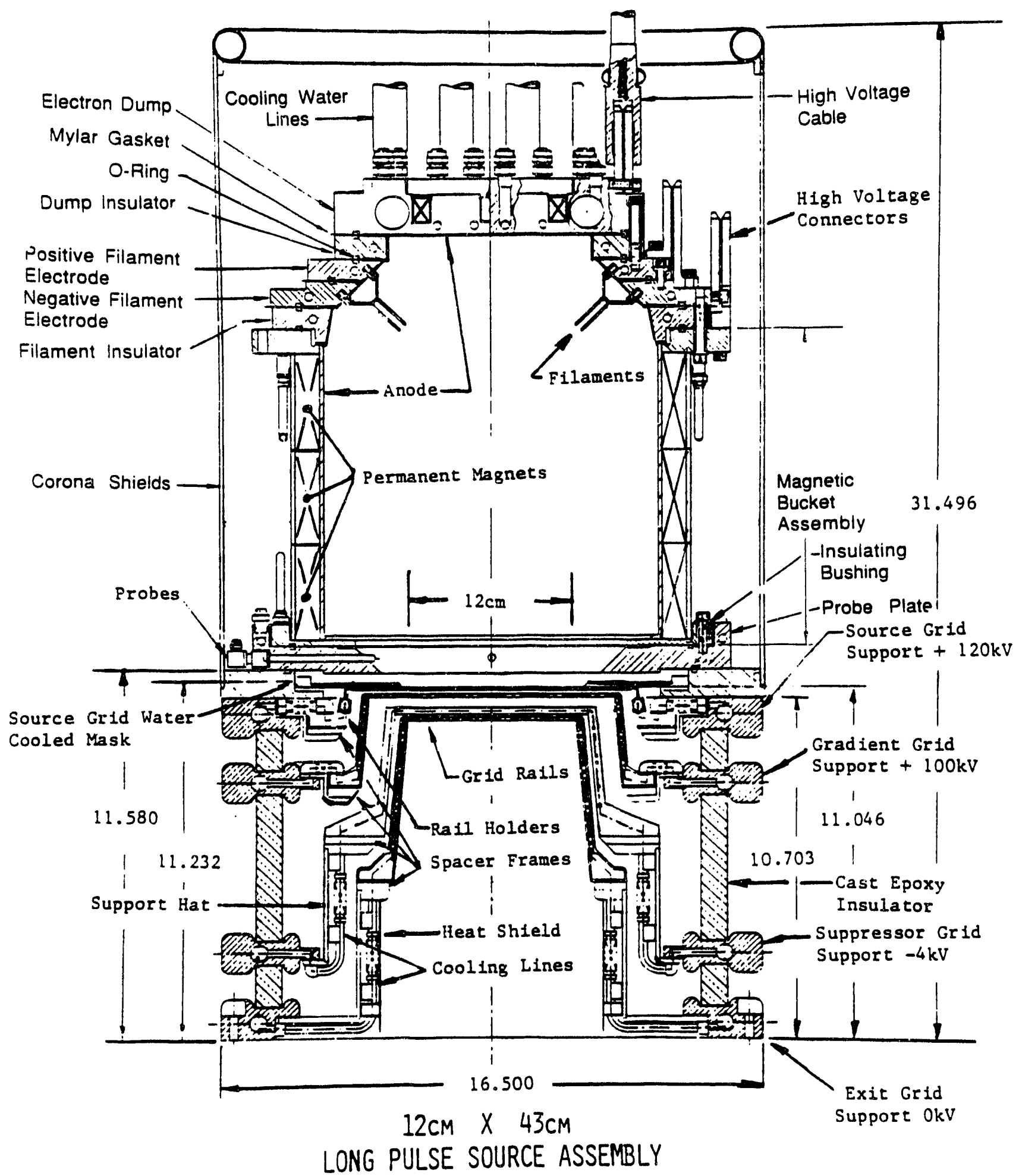

Fig. 1 


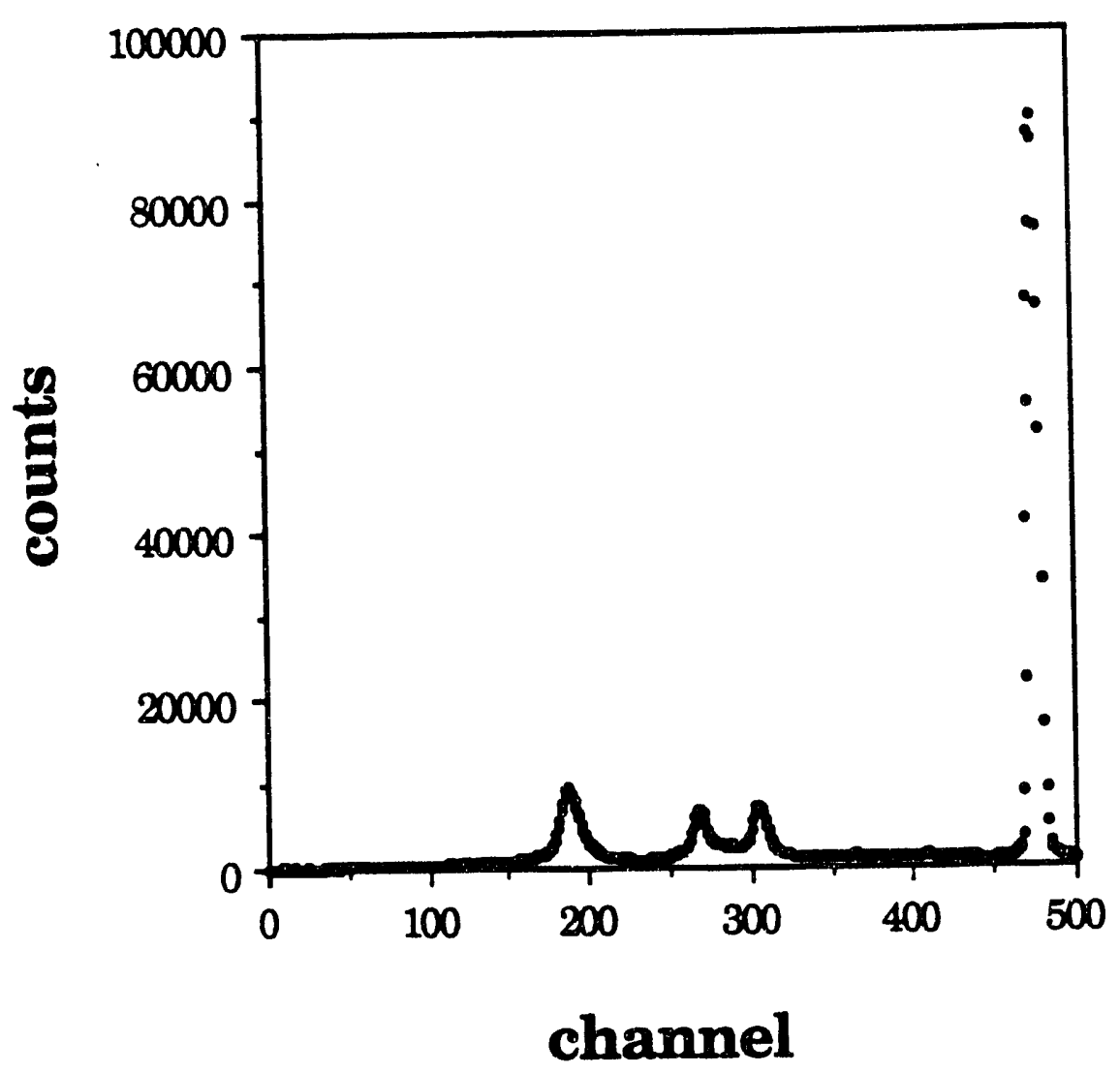

Fig. 2 


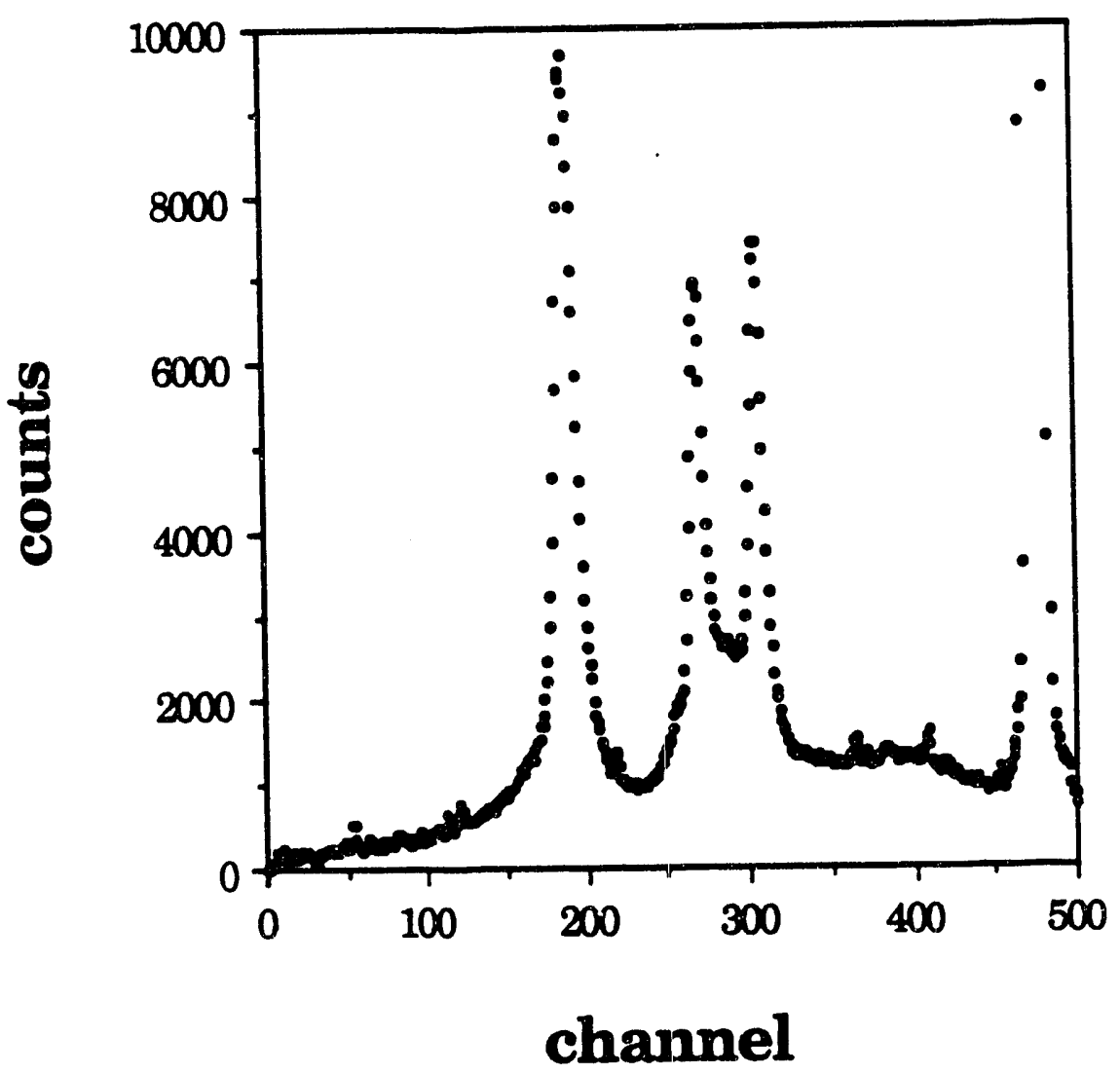

Fig. 3 


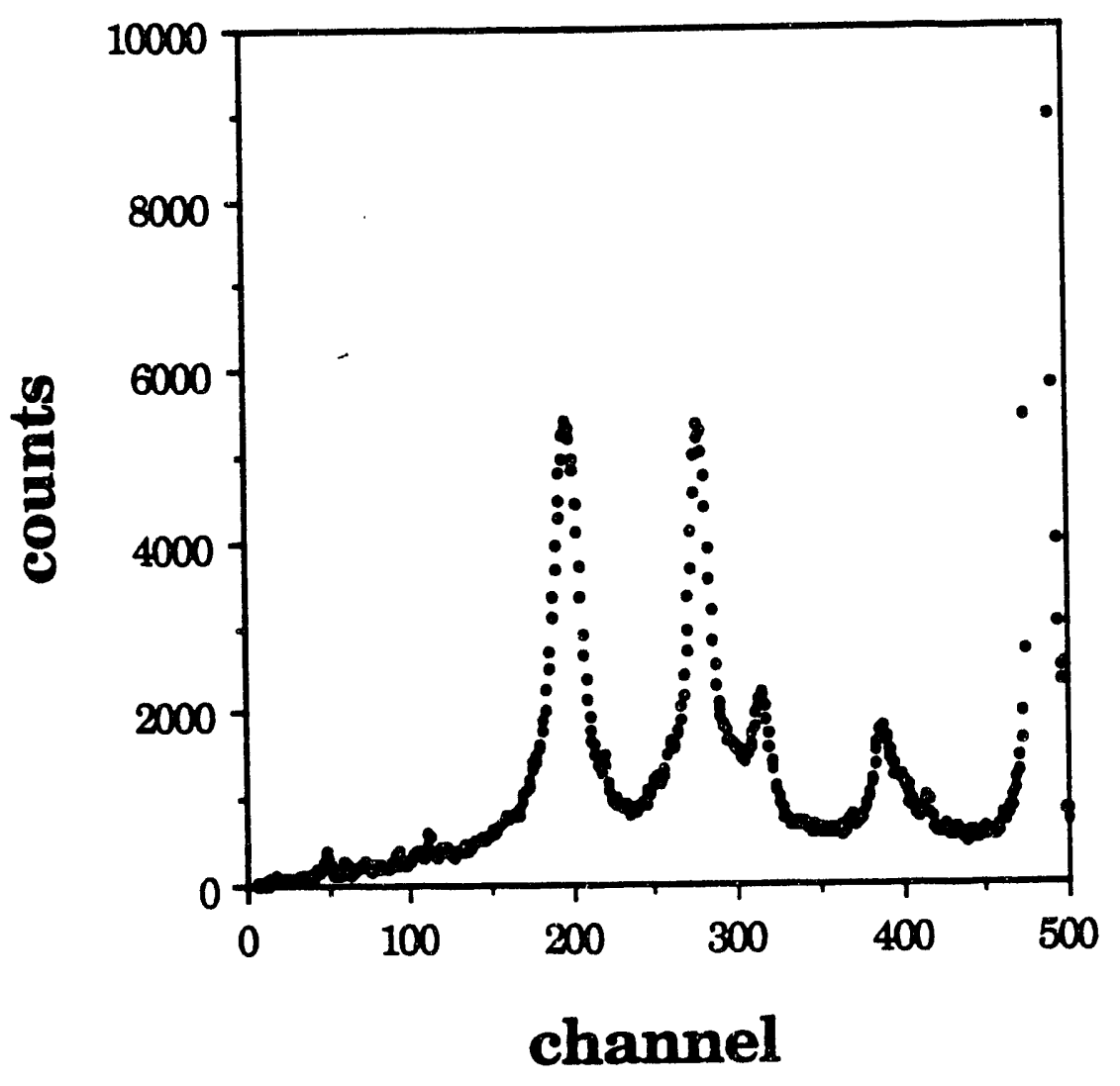

Fig. 4 


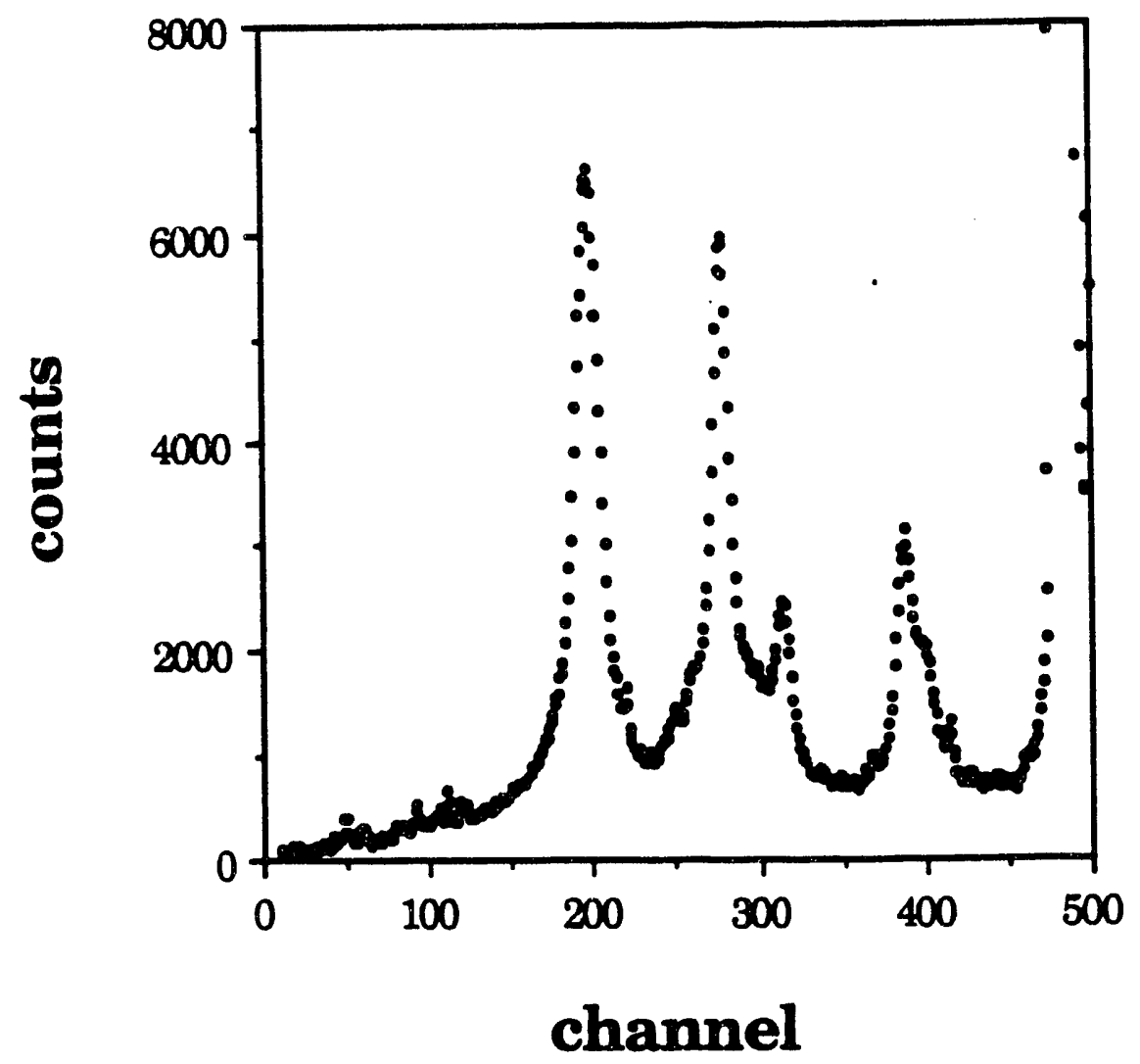

Fig. 5 


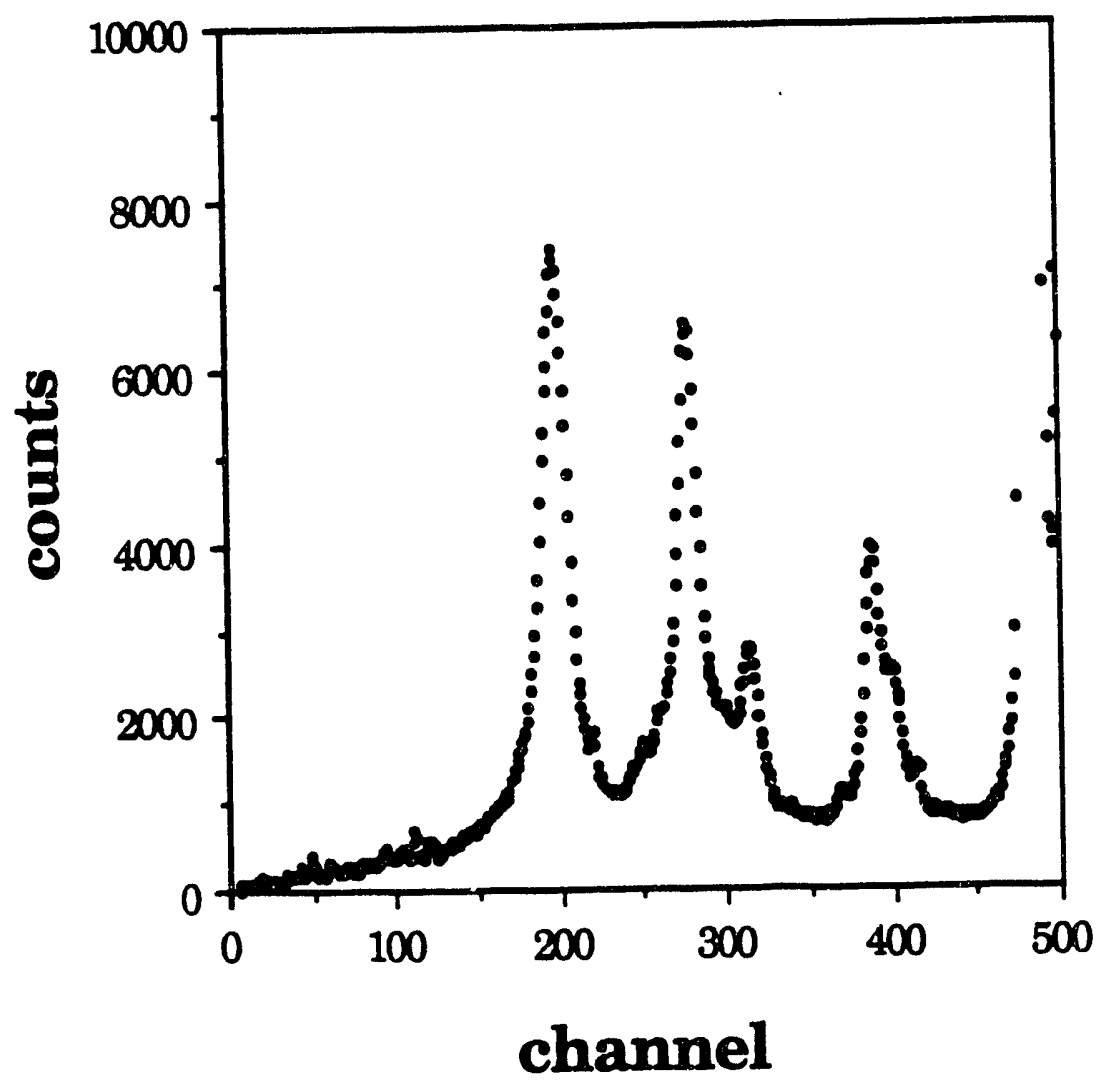

Fig. 6 


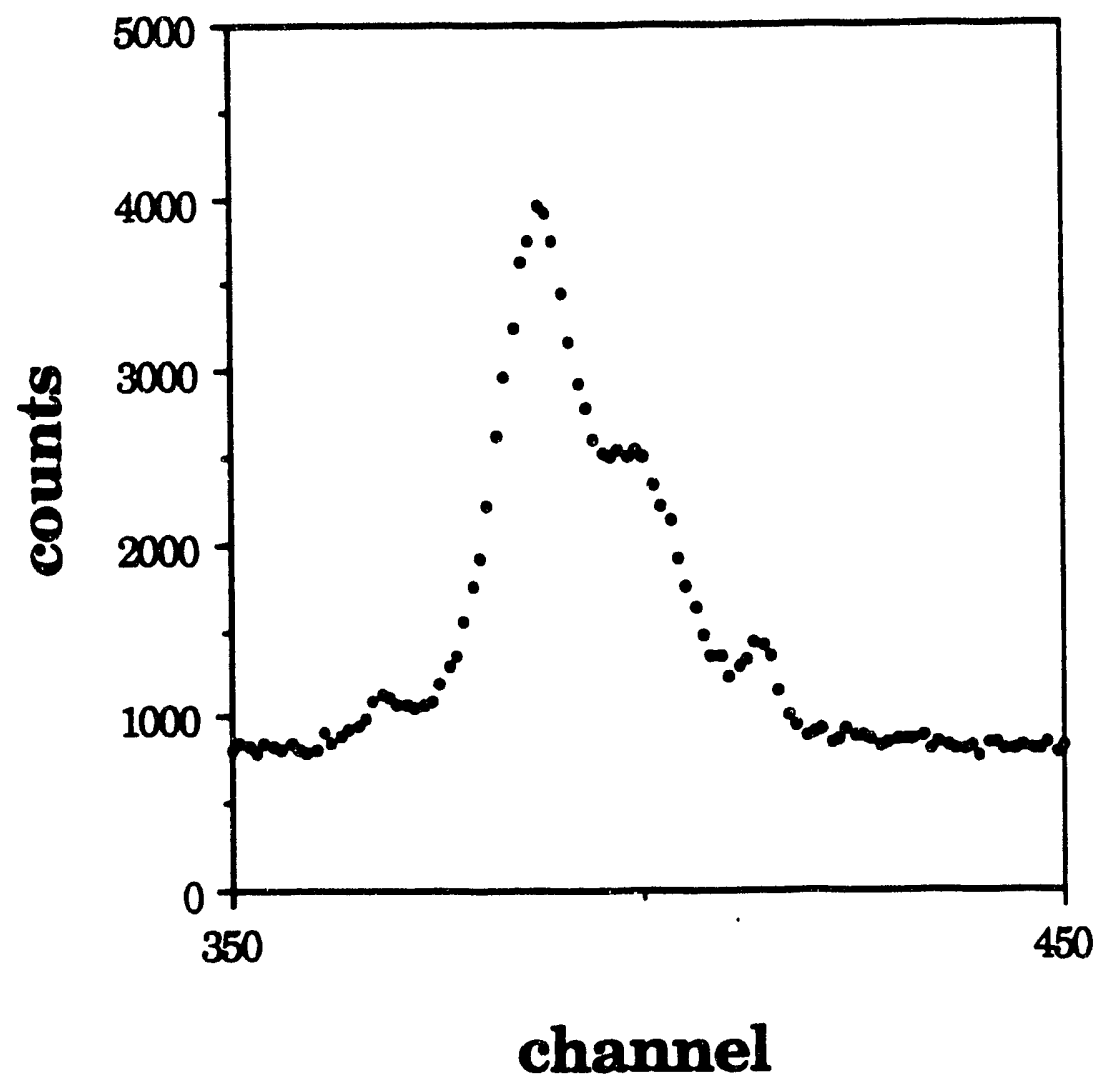

Fig. 7 


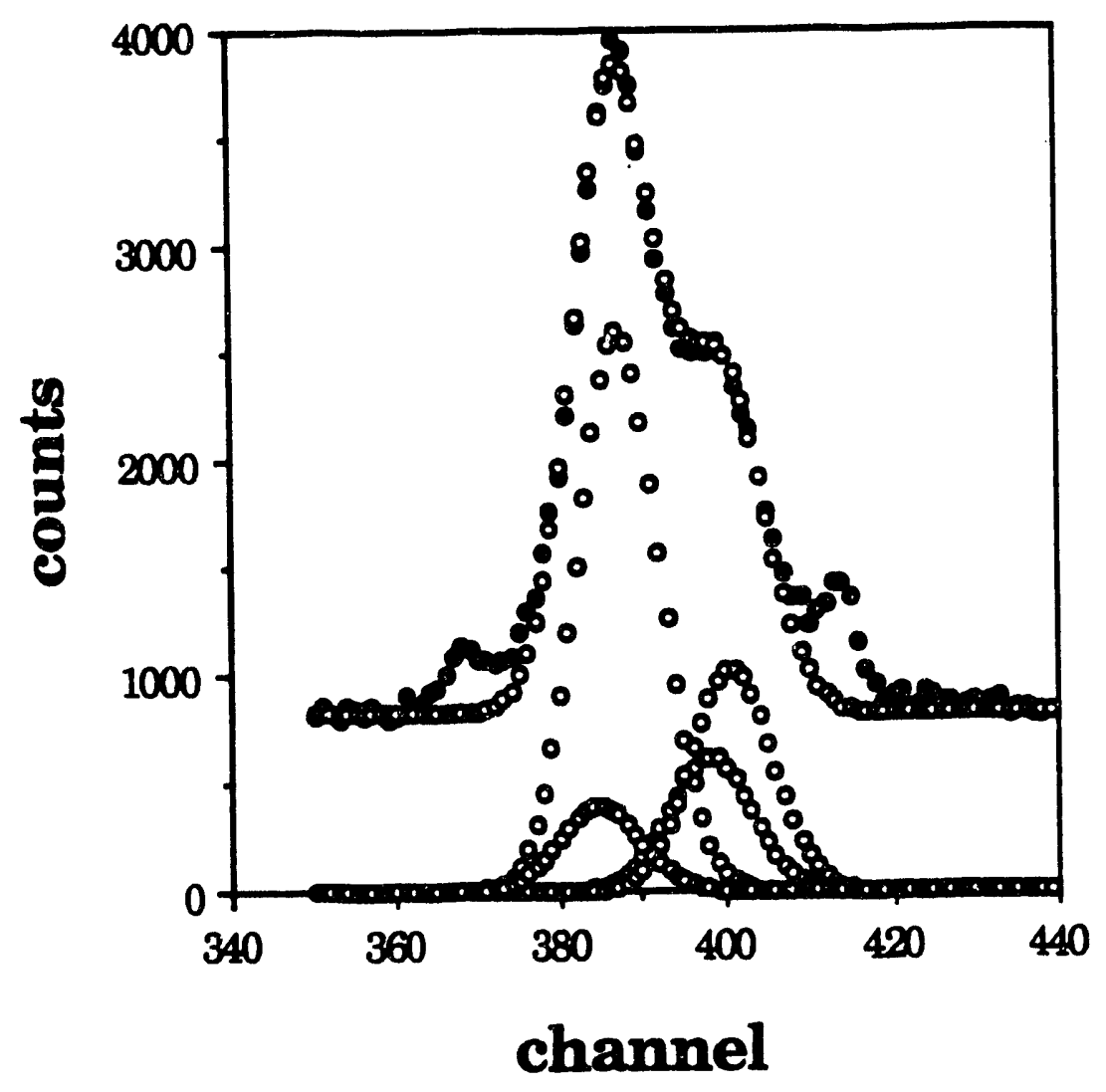

Fig, 8 


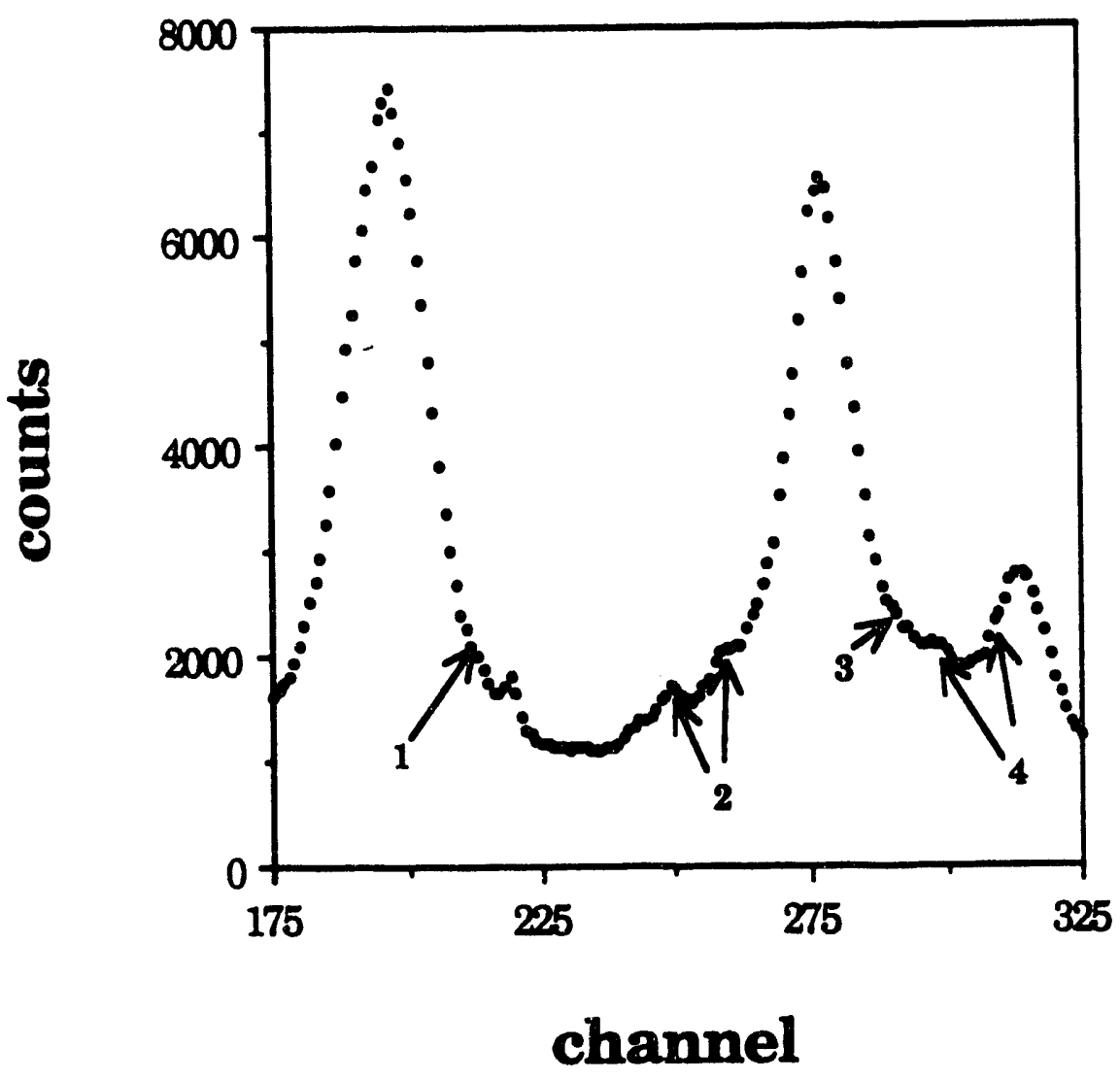

Fig. 9 


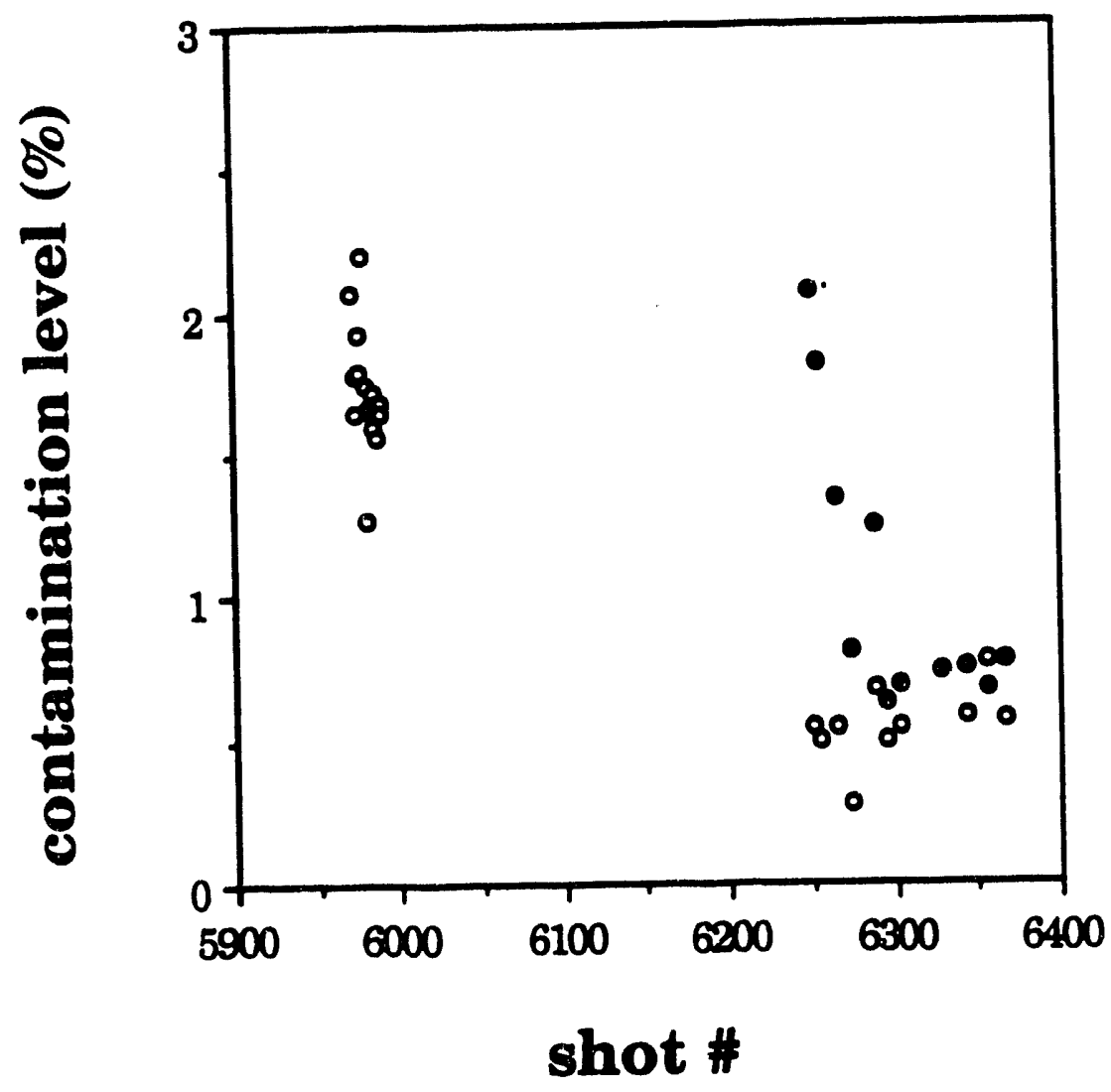

Fig. 10 


\section{EXTERNAL DISTRIBUTION IN ADDITION TO UC-420}

Dr. F. Pedon, Univ. of Woliongong, AUSTRALLA

Prol. M.H. Exemmon, Univ. of Sydroy, AUSTRuLla

Pleama Rosenech Lob., Austrien Nat. Univ., AUSTRALIA

Prof. I.R. Jones, Findere Univ, AUSTRaLlA

Prot. F. Cop, Inst tor Theornded Plyyics, AUSTRIA

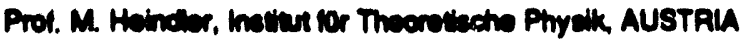

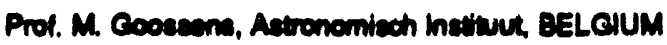

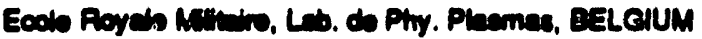

Commiacion-Europern, DC XIfFulion Pros. BELCIUM

Prot. R. Boudequs, Remeunineminin Cone, BELCIUM

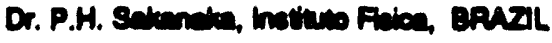

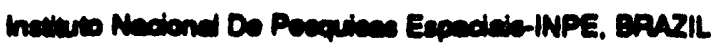

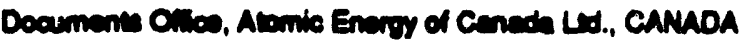

Dr. MP. Exhyndd, MPB Technobecios, Ine., CAMLOA

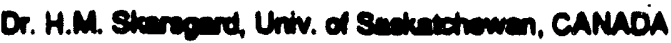

Prof. J. Teichnem, Univ. of Montred, CANADA

Prof. S.R. Sremivenan, Uhiv. of Celomy, CANADA

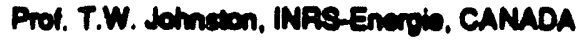

Dr. R. Bowen, Contre conadien do tuion maonstique, CANADA

Dr. C.R. Lenses, Univ. of Aberta, CAMAOA

Dr. P. Luble, Komenchervo Untwereste, CZECHOSLOVAKIA

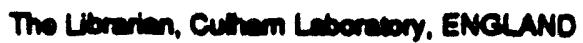

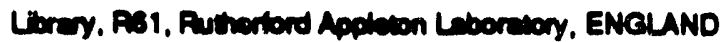

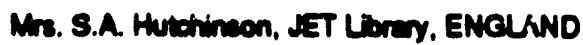

Or. S.C. Sheme, Univ. of Scum Pacific, FWI ISLANDS

P. Mremen, Univ. of Heleinti, FINLAND

Prot. M.N. Bunesos, Ecols Potychniqun., FRANCE

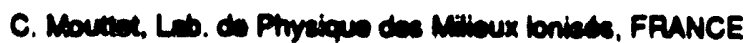

J. Radite CENCADARACHE - Bat 506, FRANCE

Prot. E. Economou, Univ. of Crom, GREECE

M. C. Pinni, Unw. of lomonina CREECE

Dr. T. Mud, Aondamy Eviographic Ser. HONG KONG

Preprint Librey. Hunoarien Academy of So.. HUNGAPY

Dr. B. Oescupu, Sern het of Nucher Phycios, INDIA

Dr. P. Kew, Inet. for Pleema Pesearch, INOU

Dr. P. Roweney, lered has of Technology, ISRAEL

Libreion, inswatend Center for Theo Phyrics, ITALY

Miss C. De Pab, Ascociaciona EURATOAENEA, ITALY

D. G. Groceo, leture d Ficice ded Pinema, ITALY

Prot. G. Powenoni, laturo Cas loniezra Dal CnP, ITALY

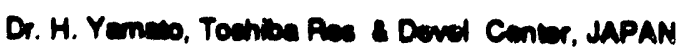

Prof. I. Kemakend, Hirochime Univ., JAPAN

Prol. K. Nlatikema thoehimo Univ., JAPAN

Directer, Jepen Alomic Enargy Rocearch Inst, LAPAN

Prof. S. Ion. Kyerew Univ., JAPAN

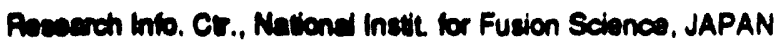

Prot. S. Teneke, Kyos Univ., JAPAN

Liverey, Kyos Univ., MAPAN

Prot. N. Inow, Univ. of Tolyo, LAPAN

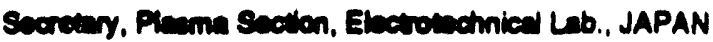

8. Mori, Tectulied Adricer, MAEP, LAPAN

D. O. Mned, Kunameso male of Technology. JAPAN

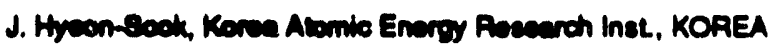

D.I. Chad, Tho Korea Adv. lnet of Sal. Tech., KOPEA

Prot. 8.S. Liby, Uniw. of Weikato. NEW ZEALAND

Inet of Plyrica, Chinese Acad SA PEOPLE'S REP. OF CHINA

Lurey, Inat of Plasma Plyzics, PEOPLE'S REP. OF CHINA

Teingtue Univ. Liorey, PEOPLE'S REPUBUC OF CHINA

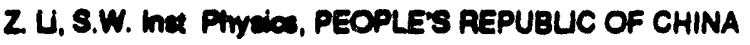

Prof. J.A.C. Cebred, Inewno Superior Tcenico, POATUGAL

Dr. O. Ponus, al I cuza Univ., Romania

Dr. J. do Vumere, fudion Suclise, AEC, S. AFRICA

Prot. M.A. Hemberg, Univ. of Nated, S. AFAICA

Prot. D.E. Km, Poheng hat of Sai. \& Tech., SO. KOPEA

Prot. C.I.E.MA.T, Fuion Divition Librery, SPAIN

Dr. L. Simnib, Univ. Of UMEA, SWEDEN

Librery, Royd inct of Tectmology, SWEDEN

Prof. H. Wimedeneon, Chemens Univ. of Tech., SWEDEN

Cerrse Phys. Des Plames, Ecolo Polytech, SWITZERLAND

Biblothed, inct. Voor Plasma-Fyeice, THE NETHERLANDS

Aeet Prot. Dr. S. Cokir, Midd Eeat Tech. Univ., TUAKEY

Dr. VA. Culthing,Sol. Res. Inat Enctrophye.I Apparatus, USSR

Dr. D.D. Ryurew, Siberian Brench of Academy of Sai., USSA

Dr. G.A. Eiverv, I.V. Kurchatov Inst, USSA

Lurarion, Tho Utr.SSA Academy of Scioncos, USSA

Dr. LM. Kovitannykh, Inat. of Gonerd Physics, USSR

Kemtorechungecenlese GmbH, Zentrabibliothek, W. GERMANY Bibliothot, Inet FO Plasmatorchung. W. GERMANY

Prof. K. Schinder, Ruhr-Unimarity Bochum, W. GEAMANY

Dr. F. Weonar, (ASOEX), MuX-Plandk-Inetitut, W. GERMANY

Lbrevion, Max-Plenok-Inotitu, W. GERMANY

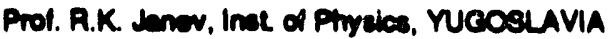



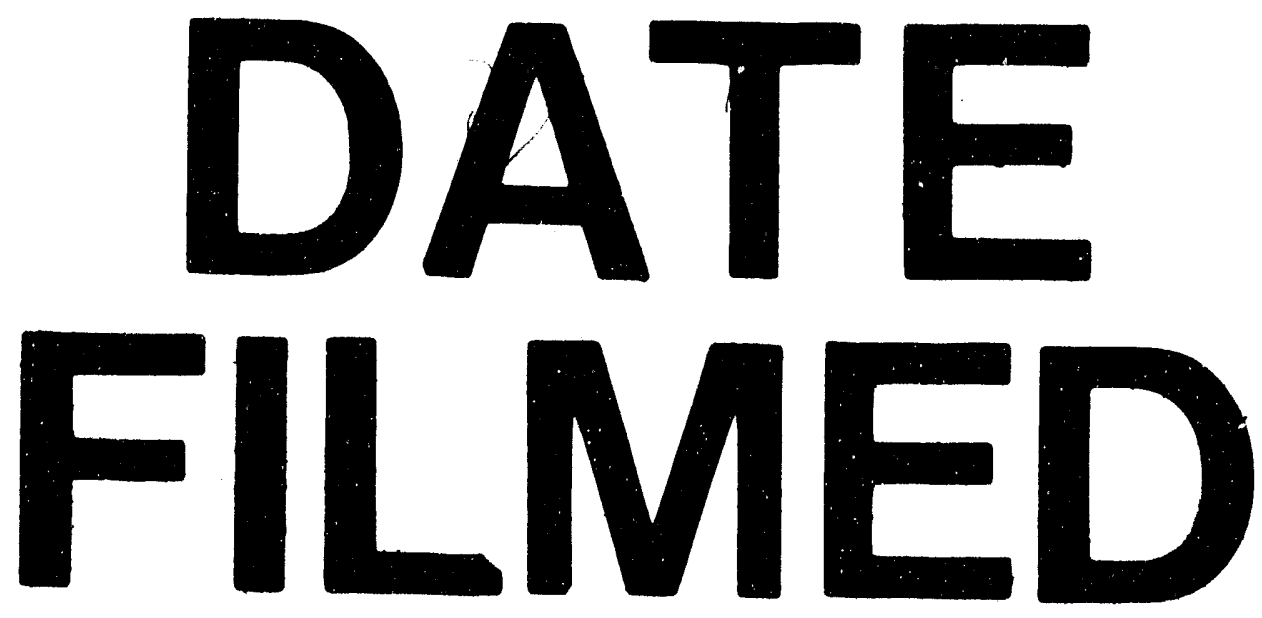

6
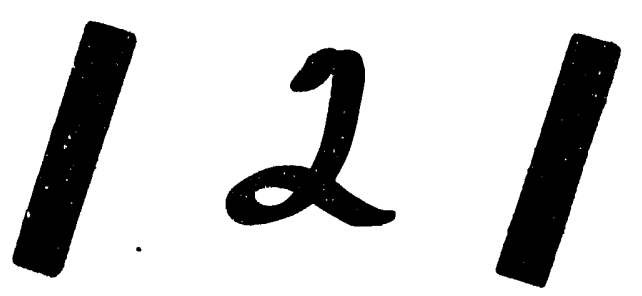

93 
